\title{
Marine protection and meadow size alter fish herbivory in seagrass ecosystems
}

\author{
Patricia Prado ${ }^{1,4, *}$, Simone Farina ${ }^{1}$, Fiona Tomas $^{2}$, Javier Romero $^{3}$, Teresa Alcoverro $^{1}$ \\ ${ }^{1}$ Centro de Estudios Avanzados de Blanes, Consejo Superior de Investigaciones Científicas, c/ Accés a la Cala St. Francesc 14, \\ 17300 Blanes, Girona, Spain \\ ${ }^{2}$ Instituto Mediterraneo de Estudios Avanzados (IMEDEA, CSIC), c/ Miguel Marqués 21, 07190 Esporles, Islas Baleares, Spain \\ ${ }^{3}$ Departamento de Ecología, Facultad de Biología, Universidad de Barcelona, Avda, Diagonal 645, 08028 Barcelona, Spain
}

${ }^{4}$ Present address: Dauphin Island Sea Lab, 101 Bienville Boulevard, Dauphin Island, Alabama 36528, USA

\begin{abstract}
In this study, we examine the hypotheses that the size of the seagrass meadow and marine protection influence the abundance of seagrass herbivores and their associated grazing pressure. The effect of meadow size was tested in 9 shallow unprotected meadows of Posidonia oceanica encompassing a wide range of areas. The effect of fishing protection was examined by comparing 9 unprotected meadows (controls) with 3 marine protected areas (MPAs) with at least 20 yr of protection that also varied in meadow size (large $>3$ ha, medium 1 ha $<x<2$ ha and small $<1$ ha). At each site, we quantified the abundance, size distribution and grazing pressure of the 2 most important herbivores, the fish Sarpa salpa and the sea urchin Paracentrotus lividus. A strong negative relationship between meadow size and both the abundance and grazing rates of $S$. salpa was evident in the unprotected meadows, but no effects were detected on either the abundance or grazing rates of $P$. lividus. Results also showed that populations of $S$. salpa (mainly large individuals) benefit from fishing protection and tended to concentrate in MPAs (with the exception of Port-Cros), resulting in enhanced grazing pressure. In $P$. lividus abundances or size distributions did not present any significant difference between protected and unprotected areas, although most MPAs presented low sea urchin densities. While MPAs are important to preserve seagrass ecosystems, results from this study indicate that it is crucial to account for the size of these habitats, particularly when functional aspects of seagrass habitats are so strongly altered by size.
\end{abstract}

KEY WORDS: Seagrass herbivory - Fishing protection · Meadow size • Posidonia oceanica • Sarpa salpa $\cdot$ Paracentrotus lividus

Resale or republication not permitted without written consent of the publisher

\section{INTRODUCTION}

The role of fishing in modifying ecosystem functions has been the subject of considerable research, as marine ecosystems collapse under the increasing pressure of the global demand for fish (Pauly et al. 2002). In the face of the declines in fish populations, the no-take marine reserves have emerged as an important tool in the management and conservation of marine communities, with a range of documented benefits to ecosystems as well as to resource-dependent stakeholders. Results of empirical studies show increased density and/or size of target species within reserves compared to fished areas (Halpern \& Warner 2002), spillover of fish across reserve boundaries (Roberts et al. 2001, Abesamis \& Russ 2005) and changes in important ecosystem functions, such as herbivory, following fishing bans (Sala et al.1998, Shears \& Babcock 2003). A considerable body of conceptual and practical research tools has evolved to determine the size and distribution of these protected areas that maximizes those benefits. Large marine protected areas (MPAs) may be ideal for biodiversity conservation because they encompass more species, but they are occasionally implemented due to underexploitation of fish stocks. On the other hand, small MPAs may provide a protective 
umbrella for the biodiversity of sedentary species but are unlikely to provide an effective refuge for highly mobile, exploited species (Hilborn et al. 2004). While considerable research has focused on the effect of MPA size on exploited populations, not much attention has been paid to the impacts of size of the protected area on ecosystem functions. Important ecosystem functions, such as herbivory, could be strongly affected by the size of a protected area, as we discuss later, and can lead to sometimes unexpected negative consequences for the habitat of intended protection.

Herbivory plays a vital role in terrestrial and aquatic systems and is of particular importance in marine habitats where grazing rates can be more than 3 times higher than in terrestrial systems (Cyr \& Pace 1993). Herbivores act both directly, by reducing plant biomass, and indirectly, by inducing nutrient export, and modifying plant production and decomposition rates (Valentine \& Heck 1999). Increased rates of herbivory (overgrazing events) can result in significant alterations in the structure and functioning of marine ecosystems (Peterson et al. 2002). Similarly, reduced grazing rates caused by overfishing and disease can also lead to major changes in ecosystem functioning, such as the dramatic 'phase shifts' witnessed in many coral reefs (review by Szmant 2002). While it is clear that MPAs can modify plant-herbivore interactions, no general trend seems to exist, since habitat protection can impact herbivores in very different ways. While sea urchin populations seem to decrease as a result of the increase of sea urchin predators (Sala et al. 1998, Pinnegar et al. 2000), other organisms, such as herbivorous fishes or large herbivorous vertebrates (dugongs, turtles and others), benefit from the protection and are the dominant herbivores in fishing-protected areas (Pinnegar et al. 2000, Jackson et al. 2001, Kirsch et al. 2002, Tomas et al. 2005). In seagrass ecosystems, the evidence indicates that herbivore distribution is highly influenced by fishing pressure. In a recent study in tropical seagrass meadows, fish herbivory was mostly restricted to unfished seagrass meadows, while sea urchin herbivory took place in fished as well as unfished areas where fish appeared not to be effective urchin predators (Alcoverro \& Mariani 2004). This trend has also been observed in other fishingprotected tropical settings where herbivorous fishes, not sea urchins, are the dominant herbivores (Valentine \& Heck 1999, Kirsch et al. 2002). Since urchins and herbivorous fishes differ in feeding mechanism and behavior (Ogden \& Lobel 1978), habitats affected primarily by urchins may differ significantly from those affected primarily by herbivorous fishes.

Habitat size is another aspect that plays an important role in plant-herbivore interactions. Herbivore densities and associated grazing pressure can either in- crease or decrease with decreasing availability of plant resources. The main mechanisms behind such potential behaviors are differential recruitment, predation and migration occurring as a function of habitat size (Bender et al. 1998). A commonly observed pattern is one in which herbivore densities increase with increasing habitat size, potentially driven by increasing resource availability (Tahvanainen \& Root 1972, Root 1973). This trend assumes that herbivores are able to move freely across the landscape mosaic and can modify their foraging behaviour and distribution to maximize resource acquisition at the landscape level. Under different conditions, however, herbivores tend to concentrate on smaller habitat patches (Hambäck \& Englund 2005, Otway et al. 2005). This crowding behaviour is often associated with reduced predation pressure in small habitat fragments (Kondoh 2003), differential migration behavior of herbivore species (Bowman et al. 2002) and distinctive sensorial developments to detect the available vegetation resources during the foraging process (Bukovinszky et al. 2005). While these behaviours, and the resulting distribution and grazing patterns, have been frequently explored in terrestrial ecosystems, little is known concerning marine ecosystems. This is surprising, as these issues may have a very relevant influence in the generalized context of coastal habitat deterioration.

In the present study, we seek to understand how the establishment of MPAs and particularly their interaction with meadow size - a function of meadow area and seagrass cover - can influence the abundance of herbivores and the resulting grazing impact on seagrass ecosystems. The present study was conducted in shallow meadows of the dominant Mediterranean seagrass Posidonia oceanica (L.) Delile of different sizeclasses and located inside and outside no-take MPAs. The main Mediterranean herbivores, the Sparid fish Sarpa salpa (L.) and the sea urchin Paracentrotus lividus (Lmk.), are potentially affected by the establishment of MPAs: S. salpa populations are a common non-target species caught in fishing nets (GarcíaRubies 1997), whereas P. lividus have been reported to be heavily predated in MPAs (Sala 1997).

\section{MATERIALS AND METHODS}

Sampling design and study sites. The effect of marine protection and its interaction with meadow size was investigated in 12 Posidonia oceanica shallow meadows in the northwest Mediterranean (Fig. 1) following an asymmetrical sampling design. Thus, within sites of small seagrass meadow size $(<1$ ha), 1 meadow in a protected area (Banyuls) was compared to 3 unprotected (control) meadows (Fenals, Giverola and Ju- 


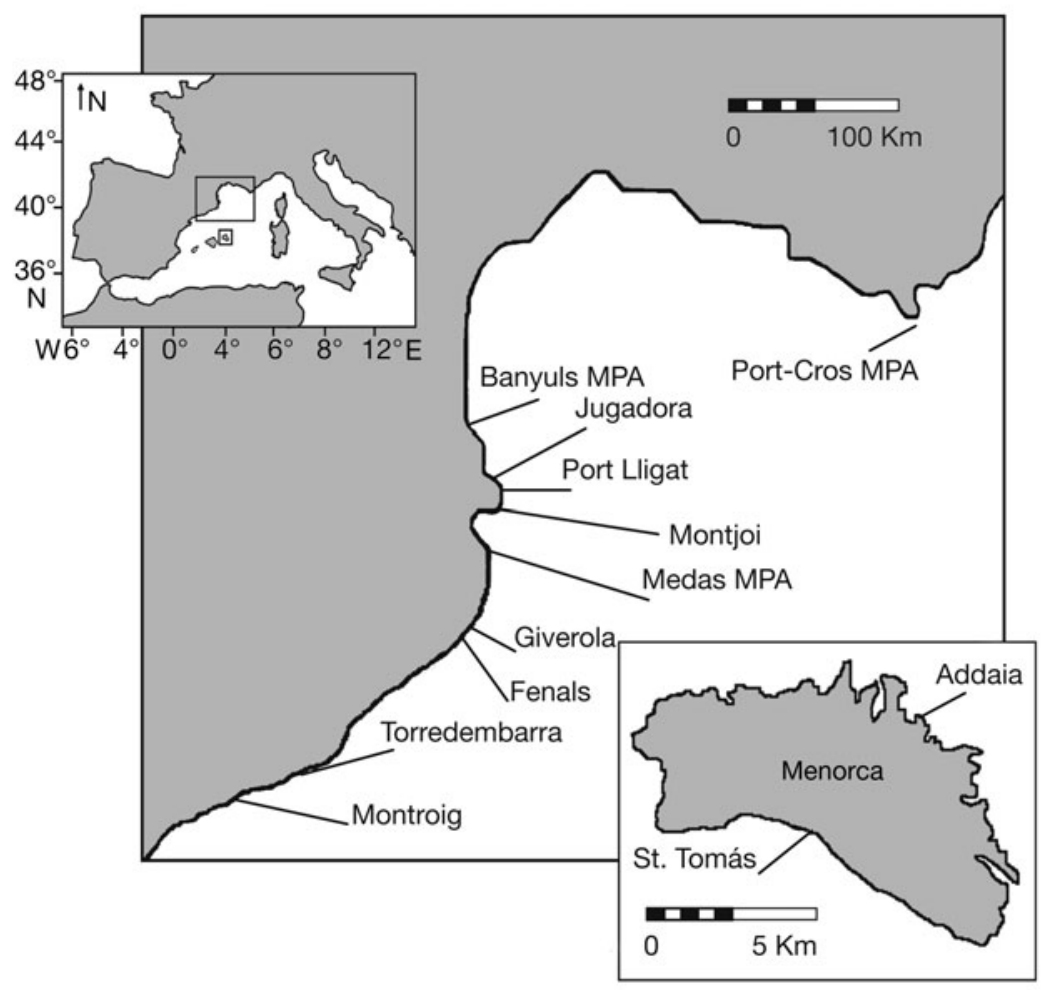

Fig. 1. The northwest Mediterranean showing the 12 study sites along the Catalan coast, the south of France and Menorca (Balearic Islands). Small seagrass meadow sites: Banyuls (marine protected area, MPA), Jugadora, Giverola and Fenals; medium meadow sites: Medes Islands (MPA), Montjoi, Port Lligat and Torredembarra; large meadow sites: Port-Cros (MPA), Santo Tomás, Addaia and Montroig pers. obs.). As far as we are aware, there is no significant sea urchin extraction in any of the meadows studied, as sea urchin harvesting in Catalonia mostly occurs in shallow rocky bottoms.

The present study was purposely conducted in (1) summer, from midJune to mid-August, since this period concentrates the largest herbivore activity, especially that of the fish Sarpa salpa (Tomas et al. 2005, Prado et al. 2007) and (2) in shallow meadows, within 0.5 and $10 \mathrm{~m}$ depth, which are known to assemble the majority of fish and sea urchin individuals (Francour 1997, Tomas et al. 2005).

Estimation of meadow size. At all sites, the study area was established according to the shallow home range occupation of Sarpa salpa during the summer period (i.e. max. 4.3 ha; Jadot et al. 2002, 2006). The extension of seagrass meadow habitat (between $0.5 \mathrm{~m}$ and $10 \mathrm{~m}$ depth) and within an area of 4.3 ha was obtained from available local cartography, considering the presence of Posidonia oceanica meadows as the entral point of the fish home range. This area was then multiplied by seagrass cover to obtain the effective meadow gadora). Similarly, within sites of medium seagrass meadow size (between 1 and 3 ha), 1 meadow in a protected area (Medes Islands, 1 ha $<x<2$ ha) was compared to 3 unprotected meadows (Torredembarra, Monjoi and Port Lligat). Finally, within sites of large seagrass meadow size ( $>3 \mathrm{ha}), 1$ meadow in a protected area (Port-Cros) was compared to 3 large unprotected meadows (Addaia, Santo Tomás and Montroig). All the considered MPAs have been effectively protected for more than 20 yr (Augier \& Boudouresque 1976, Bell 1983, Ros et al. 1984). This period ensures an effective recovery of the fish populations (abundances and sizes), including herbivore groups (McClanahan \& Arthur 2001) and the recovery of eventual top-down control on sea urchins (McClanahan 2000). For the Port-Cros MPA only, professional fishing and sport fishing (at least partially) are authorized within the park limits. However, sampling was conducted in shallow seagrass meadows adjacent to the Rascas Islet, located within a vast marine area where all types of fishing and anchoring activities are prohibited. One of the control sites, Jugadora, is inside a relatively recently declared marine reserve ( 4 to $5 \mathrm{yr}$ prior to the present study), although traditional fishing is permitted, and signs of fish recovery are not yet apparent (authors' size (in terms of seagrass availability), as very often meadows were highly fragmented (see Table 1). Seagrass cover was assessed within eighteen $50 \times 50 \mathrm{~cm}$ haphazardly located quadrats.

Although the adult home range for adult sea urchins is quite different, the same meadow sizes were used

Table 1. Seagrass area, percentage cover and the resulting meadow size (MS) at each study site. Banyuls $=B_{;}$Fenals $=F_{;}$ Giverola $=\mathrm{G}_{;}$Jugadora $=\mathrm{J}$; Medes Islands $=\mathrm{M}_{i}$ Torredembarra $=\mathrm{T}$, Montjoi $=\mathrm{Mj}$; Port Lligat $=\mathrm{P} ; \mathrm{PC}=$ Port-Cros; $\mathrm{A}=$ Addaia; $\mathrm{St}=$ Santo Tomás; Montroig $=\mathrm{Mr}$

\begin{tabular}{|llccl|}
\hline Site & Protection & $\begin{array}{c}\text { Seagrass } \\
\text { area (ha) }\end{array}$ & $\begin{array}{c}\text { \% Cover } \\
\text { (SE) }\end{array}$ & MS (ha) \\
\hline B & MPA (small) & 2.34 & $37 \pm 4$ & 0.8658 \\
F & & 0.17 & $30 \pm 7$ & 0.051 \\
G & & 1.20 & $46 \pm 8$ & 0.552 \\
J & & 0.89 & $70 \pm 6$ & 0.623 \\
M & MPA (medium) & 2.39 & $66 \pm 6$ & 1.5774 \\
T & & 1.47 & $62 \pm 7$ & 0.9114 \\
Mj & & 3.60 & $55 \pm 3$ & 1.980 \\
P & & 3.06 & $65 \pm 4$ & 1.989 \\
Pc & MPA (large) & 4.20 & $81 \pm 7$ & 3.395 \\
A & & 3.89 & $86 \pm 4$ & 3.345 \\
St & & 3.95 & $88 \pm 3$ & 3.476 \\
Mr & & 4.20 & $84 \pm 3$ & 3.528 \\
\hline
\end{tabular}


for estimating their abundance, for reasons of comparability.

Abundance of herbivores. The abundance and size distribution of Sarpa salpa and Paracentrotus lividus at each site was investigated in summer 2003 and 2004, with the exception of the 2 sites in Menorca (Fig. 1) and the Port-Cros MPA, for which sampling was conducted in summer 2005 and 2007, respectively. The methodology used to assess populations of $S$. salpa consisted of visual fish transect censuses within the shallow range of the Posidonia oceanica meadows. Size distribution was obtained by counting individuals and assigning them to 1 of 3 size-classes: small (5 to $15 \mathrm{~cm}$ ), medium $(20$ to $30 \mathrm{~cm})$ and large $(>30 \mathrm{~cm})$ within $50 \times 10 \mathrm{~m}$ strip transects (Francour 1999). In order to incorporate the large temporal variability resulting from fish mobility patterns in this species (Jadot et al. 2002, 2006), we conducted transects at different times of the day and in successive days within the 2 sampling periods, the total number of transects being 30 (except at sites in Menorca and the Port-Cros MPA in which only 15 transects were performed). Each transect was considered an independent replicate. Fish biomass ( $\mathrm{g}$ WW $10 \mathrm{~m}^{-2}$ ) was estimated using the size-weight conversion factors given in Francour (1997) (small: 5 to $15 \mathrm{~cm}=$ $15 \mathrm{~g}$ WW; medium: 20 to $30 \mathrm{~cm}=155 \mathrm{~g} \mathrm{WW}$; large: $>30 \mathrm{~cm}=552 \mathrm{~g} \mathrm{WW}$ ). The population of $P$. lividus in each meadow was assessed with fifteen $50 \times 50 \mathrm{~cm}$ haphazardly placed quadrats each year. For the PortCros MPA only, measures of sea urchin abundance could not be conducted during the present study, and available data from Hereu et al. (2003) were used instead. In each quadrat, sea urchin test diameter without spines was measured with calipers. Individuals were separated into small $(<3 \mathrm{~cm})$ and large sizeclasses $(>3 \mathrm{~cm})$, coherently with age-dependent patterns of predation reported for this species (Sala 1997).

Seagrass herbivory. Posidonia oceanica herbivory rates were measured in summer 2005 (except for PortCros, which was measured in summer 2007) through direct estimates of leaf area loss per individual shoot. At the beginning of the study, 20 seagrass shoots were haphazardly selected at each shallow meadow, tagged for identification and connected by a series of ropes (4 per study site, connecting 5 shoots each) for easy recovery. For each shoot the number of leaves, leaf length and width and the number and type of bite marks (i.e. fish or sea urchin; Prado et al. 2007) were measured underwater without detaching the shoot. All shoots were punched at the base to evaluate leaf elongation and collected 45 d later. For each shoot, biomass loss was estimated as the difference between the initial length and that at the time of collection, corrected for leaf elongation and attributed to each herbivore accordingly to the bite mark left at the end of the leaf.
Since the objective of the present study was to account for large spatial differences, leaf losses resulting from lateral bite marks or leaf fall were not included in calculations; consequently, final herbivory values may be slightly underestimated. Herbivory rates were then transformed from length $\left(\mathrm{cm}\right.$ shoot $^{-1} \mathrm{~d}^{-1}$ ) to biomass values (g DW shoot ${ }^{-1} \mathrm{~d}^{-1}$ ) using appropriate conversion factors (Kirsch et al. 2002, Tomas et al. 2005).

Statistical analyses. The effect of seagrass meadow size on herbivore abundance and on herbivory rates of Posidonia oceanica was investigated for both herbivores (Sarpa salpa and Paracentrotus lividus) by regression analysis in which only the control sites were included. The existence of an association between herbivory rates and herbivore abundance was assessed by correlation analyses.

Asymmetrical analysis of variance (Underwood 1993) was used to investigate the effect of long-term protection on herbivore abundance (Sarpa salpa and Paracentrotus lividus) as well as on fish and sea urchin grazing rates. In such analyses, 'Protection' effects were obtained separately for small, medium and large meadows, by weighting differences in 1-way ANOVA results (Site random factor) in all study sites (4 levels) against differences in control sites (3 levels). In the case of $S$. salpa, since the effect of the fishing restriction is age-dependent (Bell 1983), both fish density and biomass ( $\mathrm{g}$ WW $10 \mathrm{~m}^{-2}$ ) were tested separately for the total number of individuals as well as for each sizeclass (i.e. small, medium and large; see above). For $P$. lividus, the effect of protection was examined following the same design for small, large and total number of individuals. Sea urchin abundances were first analyzed for interannual differences with a 1-way ANOVA and after observing no differences, the data was pooled $(F=0.482 ; \mathrm{p}>0.05)$ and included in the asymmetrical 1-way design described above.

ANOVA assumptions of normality (Chi-square test) and homogeneity of variances (Cochran's test) were not always achieved by transformation. Nonetheless, Underwood (1981) has indicated that the ANOVA $F$ statistic is robust despite violation of assumptions, provided that the working sample size is large enough. When such assumptions were not met, we set the significance level to $\mathrm{p}<0.01$ to minimize the risk of making a type II error.

\section{RESULTS}

\section{Abundance of herbivores}

The abundance of Sarpa salpa displayed great spatial variation in terms of both density of individuals (from $0.13 \pm 0.05$ [SE] ind. $10 \mathrm{~m}^{-2}$ in insular sites of 
Addaia and St. Tomás to $1.4 \pm 0.3$ [SE] ind. $10 \mathrm{~m}^{-2}$ in the Medes MPA) and biomass (from $6.4 \pm 3$ [SE] g WW $10 \mathrm{~m}^{-2}$ in Addaia to $666 \pm 243$ [SE] g WW $10 \mathrm{~m}^{-2}$ in the Banyuls MPA; Fig. 2). Densities of Paracentrotus lividus also exhibited important differences among study sites, with values ranging from $0.4 \pm 0.1$ [SE] ind. $\mathrm{m}^{-2}$ in the Port-Cros MPA to $18.8 \pm 7.2[\mathrm{SE}]$ ind. $\mathrm{m}^{-2}$ in Giverola (Fig. 3). A strong negative relationship was observed between meadow size and fish biomass in unprotected meadows $\left(\mathrm{R}^{2}=0.94\right.$, slope $=-0.012, \mathrm{p}<$ $0.001)$ but not for sea urchin densities $\left(R^{2}=0.49\right.$, slope $=-0.15, p=0.053 ;$ Fig. 4).

MPA effects on herbivore abundance and grazing showed different patterns depending on meadow sizes. In Banyuls MPA (small meadow size), total fish biomass but not density was significantly higher than in control sites (Table 2). Only large individuals were observed in the seagrass bed in the reserve (i.e. significantly higher density of individuals) and, therefore, patterns of abundance for this size-class mirrored those of the total fish biomass. In contrast, abundance
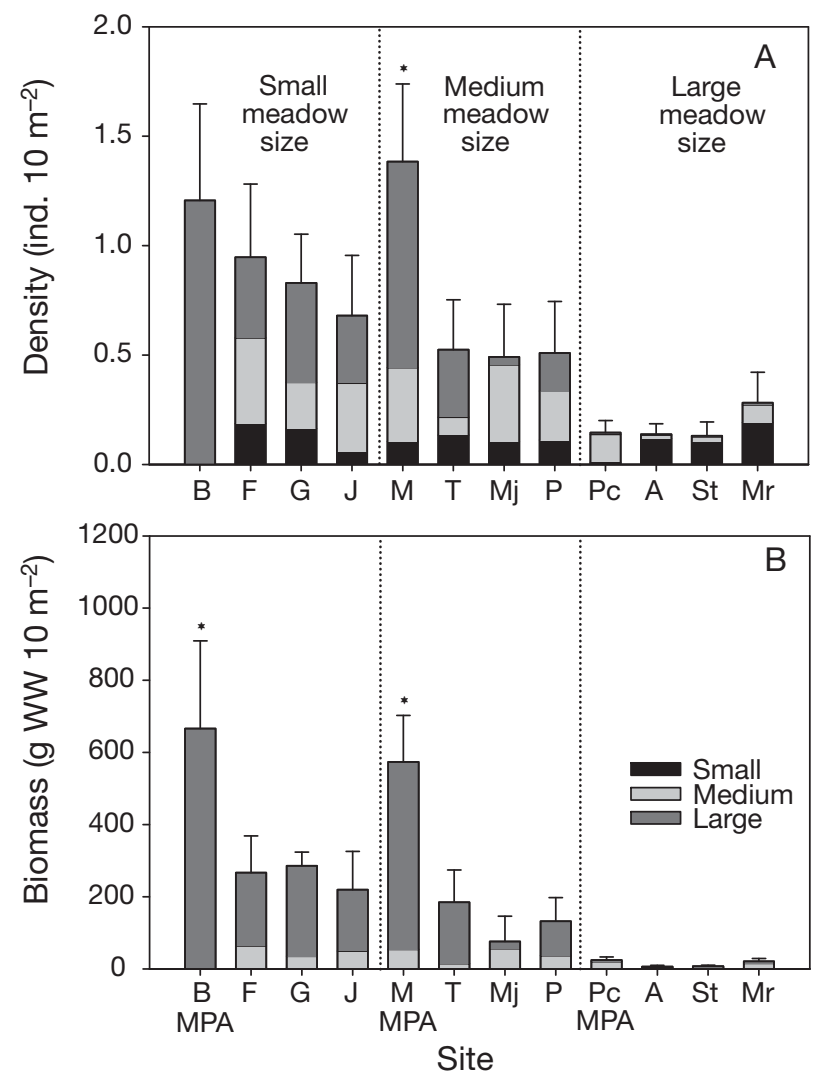

Fig. 2. Sarpa salpa. Abundance of different size-classes of S. salpa at each study site expressed as (A) no. ind. $10 \mathrm{~m}^{-2}$ and (B) biomass (g WW $10 \mathrm{~m}^{-2}$ ). ${ }^{*}$ Significant differences in total, large or medium size individuals of $S$. salpa (see Table 2) between long-term marine protection areas (MPAs) and non-reserve sites (NRs). Site names as in Table 1. Error bars are SE (both density and biomass) of medium size-classes was significantly higher in control sites, and no effect of protection was detected for the smallest size-class. In Medes MPA (medium meadow size) both total fish bio-

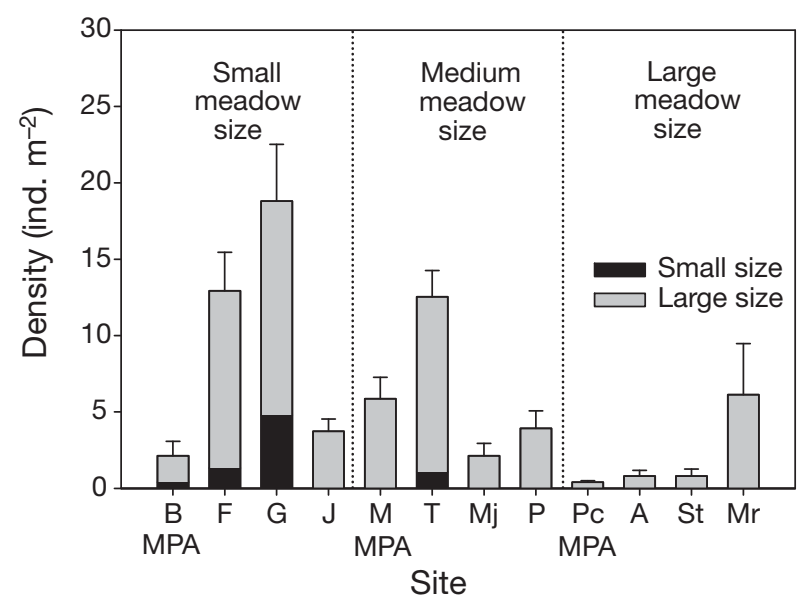

Fig. 3. Paracentrotus lividus. Densities of small $(<3 \mathrm{~cm})$ and large $(>3 \mathrm{~cm})$ individuals of $P$. lividus at each study site. Site names as in Table 1. Error bars are SE
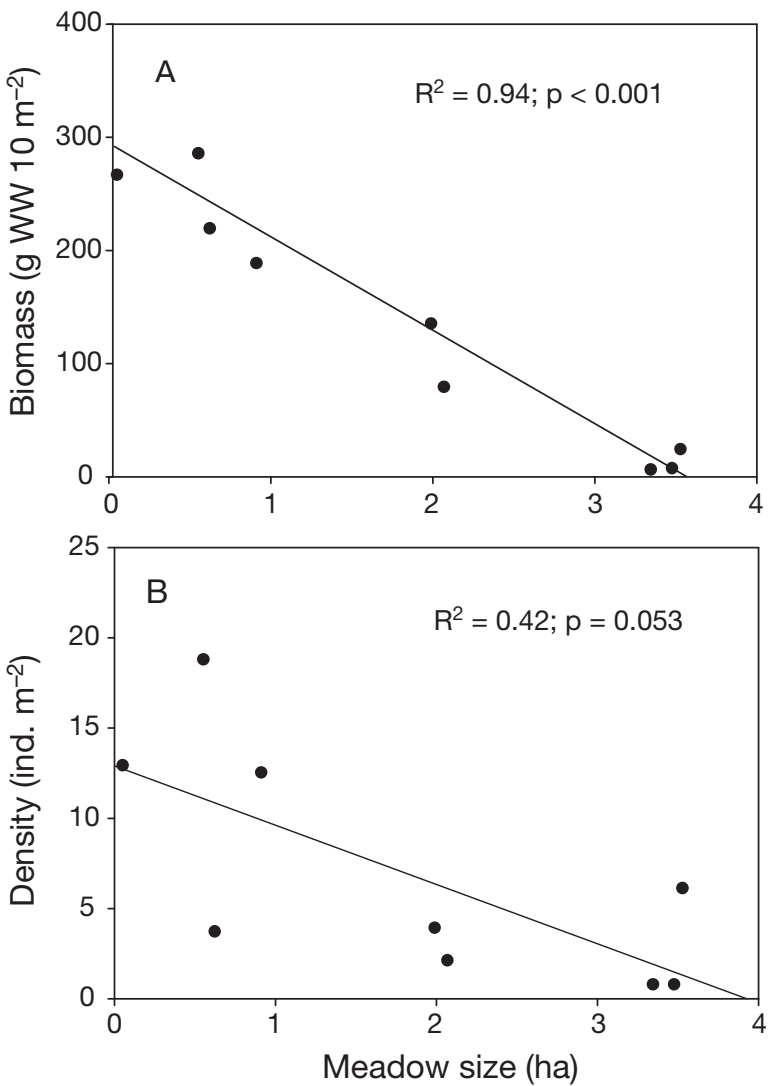

Fig. 4. Sarpa salpa and Paracentrotus lividus. Regression analyses between (A) meadow size (ha) and total biomass of $S$. salpa and (B) meadow size and total densities of the sea urchin P. lividus (control sites only) 
Table 2. Summary of asymmetric ANOVAs testing for differences in fish density (no. ind. $10 \mathrm{~m}^{-2}$ ) and fish biomass (g WW $10 \mathrm{~m}^{-2}$ ) between long-term marine protected areas (MPAs) and non-reserve sites (NRs) for each fish size-class at each meadow size (MS). ${ }^{*} \mathrm{p}<0.05,{ }^{* *} \mathrm{p}<0.01,{ }^{* * *} \mathrm{p}<0.001$

\begin{tabular}{|c|c|c|c|c|c|c|c|c|c|c|}
\hline & \multirow{2}{*}{$\begin{array}{l}\text { Source of } \\
\text { variation }\end{array}$} & \multirow[t]{2}{*}{ df } & \multicolumn{2}{|c|}{ Total fish } & \multicolumn{2}{|c|}{ Large fish } & \multicolumn{2}{|c|}{ Medium fish } & \multicolumn{2}{|c|}{ Small fish } \\
\hline & & & MS & F & MS & F & MS & $F$ & MS & $F$ \\
\hline \multicolumn{11}{|l|}{ Fish density } \\
\hline \multirow[t]{6}{*}{ Small MS } & Sites & 3 & 1.487 & 1.111 & 7.323 & 5.525 & 5.875 & 4.862 & 0.241 & 3.385 \\
\hline & Non-reserves & 2 & 0.545 & 0.644 & & 0.456 & 0.154 & 1.064 & 0.142 & 1.513 \\
\hline & MPA vs. NR & 1 & 3.37 & 6.17 & 21.63 & $130.97^{* *}$ & 17.31 & $111.93^{* *}$ & 0.439 & 3.03 \\
\hline & Residual & 29 & 2.84 & & 2.84 & & $2.7 \mathrm{E}-5$ & & $6.9 \mathrm{E}-5$ & \\
\hline & Cochran $C$ & & \multirow{2}{*}{\multicolumn{2}{|c|}{$\begin{array}{l}0.52(\mathrm{p}<0.01) \\
\text { None }\end{array}$}} & \multirow{2}{*}{\multicolumn{2}{|c|}{$\begin{array}{l}0.72(\mathrm{p}<0.01) \\
\text { None }\end{array}$}} & \multirow{2}{*}{\multicolumn{2}{|c|}{$\begin{array}{l}0.55(\mathrm{p}>0.05) \\
\text { None }\end{array}$}} & \multirow{2}{*}{\multicolumn{2}{|c|}{$\begin{array}{l}0.43(\mathrm{p}>0.05) \\
\text { None }\end{array}$}} \\
\hline & Transformation & & & & & & & & & \\
\hline \multirow[t]{6}{*}{ Medium MS } & Sites & 3 & 7.557 & 10.941 & 20.475 & 19.492 & 0.558 & 5.195 & 0.087 & 0.564 \\
\hline & Non-reserves & 2 & 0.210 & 1.636 & 0.552 & 9.776 & 0.713 & 19.935 & 0.085 & 2.599 \\
\hline & MPA vs. NR & 1 & 22.25 & $105.71^{* *}$ & 60.32 & $109.09^{* *}$ & 0.25 & 0.35 & 0.09 & 1.07 \\
\hline & Residual & 29 & 2.21 & & 0.89 & & 0.24 & & 0.48 & \\
\hline & Cochran $C$ & & \multirow{2}{*}{\multicolumn{2}{|c|}{$\begin{array}{c}0.75(\mathrm{p}<0.01) \\
\text { None }\end{array}$}} & \multirow{2}{*}{\multicolumn{2}{|c|}{$\begin{array}{c}0.64(\mathrm{p}<0.01) \\
\text { None }\end{array}$}} & \multirow{2}{*}{\multicolumn{2}{|c|}{$\begin{array}{c}0.57(\mathrm{p}<0.01) \\
\text { None }\end{array}$}} & \multirow{2}{*}{\multicolumn{2}{|c|}{$\begin{array}{c}0.73(\mathrm{p}<0.01) \\
\text { None }\end{array}$}} \\
\hline & Transformation & & & & & & & & & \\
\hline \multirow[t]{6}{*}{ Large MS } & Sites & 3 & 0.755 & 5.00 & $2 \mathrm{E}-4$ & 0.212 & 0.044 & 1.929 & 0.687 & 4.533 \\
\hline & Non-reserves & 2 & 0.901 & 4.975 & $2 \mathrm{E}-4$ & 0.295 & 0.031 & 1.809 & 0.575 & 3.067 \\
\hline & MPA vs. NR & 1 & 0.46 & 0.51 & $2 \mathrm{E}-4$ & 1 & 0.07 & 2.33 & 0.91 & 1.58 \\
\hline & Residual & 14 & $4.5 \mathrm{E}-2$ & & $2.7 \mathrm{E}-3$ & & $4.8 \mathrm{E}-2$ & & $8.2 \mathrm{E}-4$ & \\
\hline & Cochran $C$ & & \multicolumn{2}{|c|}{$0.68(\mathrm{p}<0.01)$} & \multicolumn{2}{|c|}{$0.49(\mathrm{p}<0.01)$} & \multicolumn{2}{|c|}{$0.58(\mathrm{p}<0.01)$} & \multicolumn{2}{|c|}{$0.76(p<0.01)$} \\
\hline & Transformation & & \multicolumn{2}{|c|}{ None } & \multicolumn{2}{|c|}{ None } & & & None & \\
\hline Fish biomass & & & & & & & & & & \\
\hline Small MS & Sites & 3 & 139E4 & 4.274 & 138E4 & 5.769 & 31859 & 4.869 & 206.61 & 5.006 \\
\hline & Non-reserves & 2 & 13257 & 0.091 & 1495.8 & 0.008 & 913.6 & 1.995 & 204.30 & 3.744 \\
\hline & MPA vs. NR & 1 & $414 \mathrm{E} 4$ & $312.77^{* *}$ & $521 \mathrm{E} 4$ & $3483.7^{* * *}$ & $93.74 \mathrm{E} 2$ & $102.61^{* *}$ & 211.23 & 1.034 \\
\hline & Residual & 29 & $86 \mathrm{E} 4$ & & $120 \mathrm{E} 4$ & & 33Е2 & & 7.124 & \\
\hline & Cochran $C$ & & $0.68(\mathrm{r}$ & $<0.01)$ & $0.64(\mathrm{p}$ & $0.01)$ & $0.57(\mathrm{p}$ & $<0.01)$ & $0.67(\mathrm{p}$ & ( 0.01$)$ \\
\hline & Transformation & & & ne & $\mathrm{N}$ & & & & Nor & \\
\hline Medium MS & Sites & 3 & 143E4 & 10.459 & 134E4 & 10.479 & 9571 & 3.186 & 61.46 & 0.629 \\
\hline & Non-reserves & 2 & 27792 & 0.335 & 51441 & 0.652 & 10043 & 4.966 & 40.844 & 0.436 \\
\hline & MPA vs. NR & 1 & $425 \mathrm{E} 4$ & $153.22^{* *}$ & 392E4 & $76.32^{*}$ & 8628.8 & 0.859 & 102.69 & 2.51 \\
\hline & Residual & 29 & 296E3 & & 271E3 & & 5843.5 & & 80.46 & \\
\hline & Cochran $C$ & & $0.52(\mathrm{p}$ & $<0.01)$ & $0.62(\mathrm{p}$ & $0.01)$ & $0.55(\mathrm{p}$ & 0.05) & $0.43(\mathrm{p}$ & $>0.05)$ \\
\hline & Transformation & & & ne & $\mathrm{No}$ & & No & & Nor & \\
\hline Large MS & Sites & 3 & 1738.9 & 3.50 & 46.501 & 0.212 & 1075 & 1.929 & 154.69 & 4.533 \\
\hline & Non-reserves & 2 & 2203.5 & 4.049 & 69.132 & 0.295 & 745.55 & 1.809 & 129.38 & 3.067 \\
\hline & MPA vs. NR & 1 & 809.7 & 0.36 & 1.23 & 0.0018 & 1733.9 & 2.32 & 205.31 & 1.58 \\
\hline & Residual & 14 & 1129.1 & & 153.24 & & 1170.8 & & 23.09 & \\
\hline & Cochran $C$ & & $0.48(\mathrm{p}$ & $<0.01)$ & 0.46 & 0.05) & $0.32(\mathrm{p}$ & $0.05)$ & $0.22(p$ & $>0.05)$ \\
\hline & Transformation & & No & & & & No & & Nor & \\
\hline
\end{tabular}

Table 3. Summary of asymmetric ANOVAs testing for differences in densities of small $(<3 \mathrm{~cm})$ and large $(>3 \mathrm{~cm})$ Paracentrotus lividus between long-term marine protected areas (MPAs) and non-reserve sites (NRs) for each meadow size (MS)

\begin{tabular}{|c|c|c|c|c|c|c|c|c|}
\hline & \multirow{2}{*}{ Source of variation } & \multirow[t]{2}{*}{$\mathrm{df}$} & \multicolumn{2}{|c|}{ Total urchins } & \multicolumn{2}{|c|}{ Large urchins } & \multicolumn{2}{|c|}{ Small urchins } \\
\hline & & & MS & $F$ & $\mathrm{MS}^{\mathrm{J}}$ & $F$ & MS & $F$ \\
\hline \multirow[t]{6}{*}{ Small MS } & Sites & 3 & 371.52 & 6.785 & 381.02 & 16.678 & 28.613 & 1.302 \\
\hline & Non-reserves & 2 & 246.06 & 3.483 & 173.05 & 9.836 & 36.836 & 1.27 \\
\hline & MPA vs. NR & 1 & 622.44 & 2.53 & 796.96 & 4.60 & 12.16 & 0.33 \\
\hline & Residual & 14 & \multirow{3}{*}{\multicolumn{2}{|c|}{$\begin{array}{c}65.95 \\
0.59\left(\mathrm{p}_{\sqrt{\mathrm{x}}}>0.05\right)\end{array}$}} & \multirow{3}{*}{\multicolumn{2}{|c|}{$\begin{array}{c}44.63 \\
0.50(\mathrm{p}>0.05) \\
\text { None }\end{array}$}} & \multirow{3}{*}{\multicolumn{2}{|c|}{$\begin{array}{l}0.97 \\
0.44(\mathrm{p}>0.05) \\
\quad \text { None }\end{array}$}} \\
\hline & Cochran $C$ & & & & & & & \\
\hline & Transformation & & & & & & & \\
\hline \multirow{6}{*}{ Medium MS } & Sites & 3 & 122.12 & 15.651 & 96.444 & 21.555 & & \\
\hline & Non-reserves & 2 & 179.92 & 18.756 & 143.28 & 32.034 & & \\
\hline & MPA vs. NR & 1 & 6.52 & 0.03 & 2.77 & 0.02 & & \\
\hline & Residual & 14 & 2.431 & & 4.479 & & & \\
\hline & Cochran $C$ & & \multirow{2}{*}{\multicolumn{2}{|c|}{$0.38 \underset{\sqrt{\mathrm{x}}}{(\mathrm{p}>0.05)}$}} & \multirow{2}{*}{\multicolumn{2}{|c|}{$0.44(\mathrm{p}>0.05)$}} & & \\
\hline & Transformation & & & & & & & \\
\hline
\end{tabular}






Fig. 5. Sarpa salpa and Paracentrotus lividus. Herbivory rates measured at each study site $\left(\mathrm{mg}\right.$ DW shoot $\left.^{-1} \mathrm{~d}^{-1}\right)$ : (A) total (fish and sea urchin), (B) S. salpa and (C) P. lividus. ${ }^{*}$ Significant differences in herbivory rates between long-term marine protection areas (MPAs) and non-reserve sites (NRs) for each meadow size-class (see Table 4). Site names as in Table 1. Error bars are SE

mass and density were higher than in control sites, and the same patterns of significance were observed for the large fish size-class (Table 2). No protection effect was detected for either medium or small size-class individuals. In Port-Cros MPA (large meadow size) fish biomass was apparently higher than in controls; however, this trend was not significant. No protection effect was observed for fish density. In the Port-Cros MPA both fish density and biomass were much lower than in Medes and Banyuls MPAs.
For sea urchins, MPAs caused no significant effect in total, large or small-size densities of individuals within seagrass meadows (Table 3). In the small MPA only, a trend towards lower densities of individuals was observed, but it was not significant.

\section{Seagrass herbivory}

Seagrass herbivory rates (including both herbivores) reached average values of $132 \%$ of the leaf primary production during the study period $(2.25 \pm 0.5[\mathrm{SE}] \mathrm{mg}$ DW shoot $^{-1} \mathrm{~d}^{-1}$ ), but varied from $0.6 \pm 0.2 \mathrm{mg}$ DW shoot $^{-1} \mathrm{~d}^{-1}$ in Addaia to $5.1 \pm 1.7$ [SE] mg DW shoot ${ }^{-1}$ $\mathrm{d}^{-1}$ in Giverola (Fig. 5A). Sarpa salpa, accounted for $68 \%$ of total herbivory $\left(1.53 \pm 0.4 \mathrm{mg} \mathrm{DW}\right.$ shoot $\left.^{-1} \mathrm{~d}^{-1}\right)$ and the sea urchin Paracentrotus lividus for the remaining $32 \%\left(0.71 \pm 0.3 \mathrm{mg}\right.$ DW shoot $\left.{ }^{-1} \mathrm{~d}^{-1}\right)$, but leaf biomass losses to each species were also subject to substantial variability among sites (Fig. 5B,C). Fish and sea urchin herbivory rates were both significantly correlated to fish biomass and sea urchin density, respectively ( $S$. salpa: $\mathrm{r}=0.87$, slope $=0.08, \mathrm{p}<0.01$; $P$. lividus: $\mathrm{r}=0.82$, slope $=4.3, \mathrm{p}<0.01$ ).

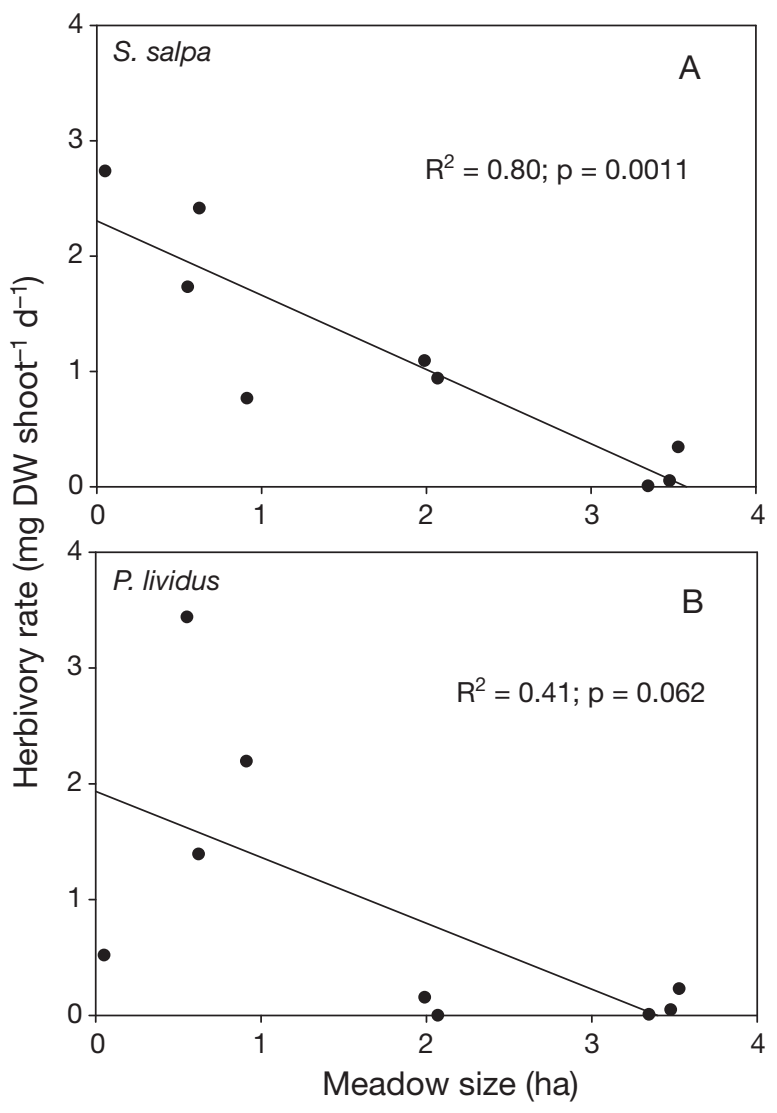

Fig. 6. Sarpa salpa and Paracentrotus lividus. Regression analyses between meadow size (ha) and herbivory rates of (A) S. salpa and (B) P. lividus (non-reserve sites only) 
Table 4. Summary of asymmetric ANOVAs testing for differences in seagrass herbivory (mg DW shoot ${ }^{-1} \mathrm{~d}^{-1}$ ) by the fish Sarpa salpa and the sea urchin Paracentrotus lividus between marine protected areas (MPAs) and non-reserve sites (NRs) for each meadow size (MS). ${ }^{*} \mathrm{p}<0.05,{ }^{* *} \mathrm{p}<0.01$

\begin{tabular}{|c|c|c|c|c|c|}
\hline \multirow{2}{*}{\multicolumn{2}{|c|}{ Source of variation df }} & \multicolumn{2}{|c|}{ Fish herbivory } & \multicolumn{2}{|c|}{ Urchin herbivory } \\
\hline & & MS & $F$ & MS & $F^{t}$ \\
\hline \multicolumn{6}{|l|}{ Small MS } \\
\hline Sites & 3 & 17.929 & 4.040 & 36.024 & 17.571 \\
\hline Non-reserves & 2 & 2.570 & 0.982 & 41.583 & 16.448 \\
\hline MPA vs. NR & 1 & 48.64 & $18.92^{*}$ & 24.90 & 0.59 \\
\hline Residual & 18 & 3.762 & & 0.467 & \\
\hline Cochran $C$ & & \multicolumn{2}{|c|}{$0.30(p>0.05)$} & \multicolumn{2}{|c|}{$0.46(\mathrm{p}<0.01)$} \\
\hline Transformation & & \multicolumn{2}{|c|}{ None } & \multicolumn{2}{|c|}{ None } \\
\hline \multicolumn{6}{|l|}{ Medium MS } \\
\hline Sites & 3 & 16.181 & 7.733 & 19.421 & 5.551 \\
\hline Non-reserves & 2 & 0.479 & 0.336 & 27.079 & 6.247 \\
\hline MPA vs. NR & 1 & 47.58 & $99.19^{* *}$ & 4.10 & 0.15 \\
\hline Residual & 18 & 4.6 & & 0.345 & \\
\hline Cochran $C$ & & \multicolumn{2}{|c|}{$0.30(\mathrm{p}>0.05)$} & \multicolumn{2}{|c|}{$0.76(\mathrm{p}<0.01)$} \\
\hline Transformation & & & & $\mathrm{No}$ & \\
\hline \multicolumn{6}{|l|}{ Large MS } \\
\hline Sites & 3 & 3.612 & 4.654 & 0.243 & 2.196 \\
\hline Non-reserves & 2 & 0.587 & 2.895 & 0.312 & 2.028 \\
\hline MPA vs. NR & 1 & 9.66 & 16.43 & 0.11 & 0.34 \\
\hline Residual & 19 & 2.254 & & & \\
\hline Cochran $C$ & & \multicolumn{2}{|c|}{$0.70(\mathrm{p}<0.01)$} & \multicolumn{2}{|c|}{$0.89(\mathrm{p}<0.01)$} \\
\hline Transformation & & \multicolumn{2}{|c|}{ None } & \multicolumn{2}{|c|}{ None } \\
\hline
\end{tabular}

have additive effects on key ecological processes such as herbivory, and that the influence of seagrass habitat loss (review by Short \& Wyllie-Echeverria 1996) and decimated populations of herbivores (review by Jackson et al. 2001) in ecosystem functioning should not be considered independently. The negative correlation between fish grazing and meadow size suggests that any loss of $P$. oceanica habitat could cause the aggregation of herbivore fishes within the remnant habitat patches, offsetting the release in grazing pressure caused by fishing in most marine systems.

Populations of the herbivorous fish Sarpa salpa, but not those of the sea urchin Paracentrotus lividus, reached higher abundance in small shallow Posidonia oceanica meadows. Accordingly, study sites with reduced seagrass abundance revealed herbivore impacts that were several orders of magnitude greater than those in large meadows. This concentration of fish can be the

Fish herbivory was significantly associated to meadow size $\left(\mathrm{R}^{2}=0.80 ;\right.$ slope $\left.=-0.64 ; \mathrm{p}=0.001\right)$ (Fig. 6A), whereas herbivory by sea urchins was not $\left(\mathrm{R}^{2}=0.41\right.$; slope $=-0.72 ; \mathrm{p}=0.062$ ) (Fig. 6B). Herbivory rates by Sarpa salpa were also affected by the protection status depending on meadow size (Table 4 ). Fish herbivory in the small and medium MPAs of Banyuls and Medes Islands was consistently higher than in control sites of the same meadow size (56 and 31\% higher, respectively). In the large MPA, there was also a trend towards enhanced fish herbivory but it was not significant. Seagrass herbivory by Paracentrotus lividus showed no significant effect of protection at any of the studied ranges of meadow size, albeit a trend towards lower rates was found again in the small MPA (Table 4, Fig. 5C).

\section{DISCUSSION}

The present study provides evidence that smaller Posidonia oceanica meadows are linked to higher fish herbivory in the western Mediterranean. Moreover, long-term protected sites featuring less than 2 ha of shallow seagrass beds (i.e. low and medium meadow sizes) have increased abundance of Sarpa salpa and display enhanced fish grazing. Hence, the results presented here provide the first empirical evidence that protection from fishing and landscape features may result of a number of processes such as differential recruitment or early mortality associated to patch size, or to movement patterns, as $S$. salpa is a relatively mobile species. Recruitment and mortality of early stages appear to be of outstanding importance in controlling the abundance of individuals (Macpherson et al. 1997), but juvenile individuals are rarely found in seagrass meadows. S. salpa recruitment only occurs in very shallow rocky bottoms (Harmelin-Vivien et al. 1995), and individuals do not feed on macrophytes until they reach a size of ca. $13 \mathrm{~cm}$ (Christensen 1978). In contrast, fish schools' movements across a mosaic of underwater habitats can account for this concentration in seagrass patches. S. salpa home range is of the order of 4 ha (Jadot et al. 2002, 2006), and mobility across different habitats has been documented (Verlaque 1990). In mobile species with comparable home range areas, negative density-area relationships have been associated with either random searching patterns (Bowman et al. 2002) or the use of visual or olfactory cues to find the resources (Bukovinszky et al. 2005). S. salpa juveniles and adults are mid-water visual foragers moving widely within their summer home range, which includes seagrass meadows, rocky substrates and sandy areas. Large schools of adult $S$. salpa are common browsers in $P$. oceanica, but also feed on a variety of benthic macroalgae (Verlaque 1990), suggesting that the availability of shallow seagrass areas does not limit the growth of fish populations. Nevertheless, large 
individuals of $S$. salpa seem to have a higher contribution of seagrass to their diet (Havelange et al. 1997) and also show a clear preference for P. oceanica compared to algae (Vergés 2007). Consequently, since S. salpa is typically found aggregating in meadows, the lower the seagrass area within the species home range, the higher the fish abundance and grazing impact will be within the seagrass bed.

In contrast, Paracentrotus lividus abundances did not show any clear abundance or activity pattern related to meadow size. Perimeter:area ratios, rather than habitat size itself, appear to influence the abundance of organisms with small movement ranges or with a foraging behavior relying on contact search (Hambäck \& Englund 2005), such as sea urchins. Particularly, for $P$. lividus, the spatial distribution of individuals appears to be dependent on both the presence of bare rhizomes (mat structure) of Posidonia oceanica for local recruitment and on the degree of connection between the seagrass and the adjacent hard substrate that facilitates the movement from the later to the former (Prado et al. 2006). It has to be taken into account that $P$. lividus does not move across large tracts of sandy habitat (Dance 1987), possibly because it would be exposed to higher levels of predation. Hence, the final within-bed population abundance and structure results from several factors including supply of individuals from adjacent rocky habitats, local bed recruitment (Prado et al. 2006) and, to a lesser extent, by processes like predation (see below). The large sea urchin abundance in some study sites with low (Fenals and Giverola) and intermediate (Torredembarra) levels of $P$. oceanica appears to be caused by landscape features (i.e. the degree of contact between habitats) inherent to those particular locations rather than by habitat dependent processes.

The MPAs of Banyuls and Medes Islands displayed a clear increase in the grazing pressure of the fish Sarpa salpa relative to unprotected meadows (ca. 56 and $31 \%$ higher than in the respective control sites). Although changes in the fish foraging behavior cannot be completely excluded to explain such differences, these are most likely related to the associated increase in fish biomass observed in MPAs relative to control sites (see Bell 1983 for similar findings). S. salpa is not a clear fishing target in the study region (GarcíaRubies 1997), but populations can be affected by conspicuous non-selective fishing practices operating in seagrass meadows (Sánchez-Jerez \& Ramos-Esplá 1996) or by fishing for commercial species (Vander Walt \& Govender 1996). More specifically, the present study indicates that protection from fishing influences S. salpa size distribution by increasing the abundance of large size-classes and decreasing that of medium size-classes, causing an overall increase in fish bio- mass. These results are coherent with many studies documenting the impacts of fishing on populations and community structure (review by Rochet \& Trenkel 2003) as well as with studies examining the benefits of no-take areas to fish populations (Roberts et al. 2001, Abesamis \& Russ 2005). Although a similar trend of fish populations and fish grazing - higher in the large MPA of Port Cros than in unprotected controls - was found, the obtained differences were not significant. This lack of significance can be accounted for by alternative explanations. First, in meadows higher than $3 \mathrm{ha}$, the influence of meadow size may mask possible increases in fish abundance. Second, it is also possible that the strength of top-down processes due to the increase of predatory species attain differential importance in MPAs of contrasting sizes. Home range sizes of fish increase with body size, and a large proportion of fish in small reserves can still be exposed to fishing mortality as they increasingly move within nonreserve areas (review by Kramer \& Chapman 1999). Hence, in spite of long-term protection, trophic linkages in small MPAs such as Banyuls (650 ha) and Medes Islands (511 ha) may still differ from that of a larger MPA such as Port-Cros (1288 ha). Finally, the lower abundance of $S$. salpa in the Port-Cros meadow may also be caused, to some extent, by the influence of fishing activities in other areas within the park boundaries.

Concerning sea urchins, many studies have shown the existence of top-down control of their populations resulting from enhanced predation in MPAs, in terms of both density (McClanahan et al. 1999, Shears \& Babcock 2003) and size distribution (Sala 1997, Sala et al. 1998). Our results only weakly suggest the existence of such an effect in the studied MPAs, but differences did not reach the signification threshold required for the very restrictive asymmetrical design used. On the one hand, some control locations exhibited very low sea urchin density not attributable to predation. In these locations other factors such as the lack of within-bed recruitment seem to explain these low densities (Prado et al. 2006). Additionally, predation inside seagrass meadows is probably less intense than that observed in rocky habitats as a result of the greater shelter. In fact, the long leaves of Posidonia oceanica have been shown to be an effective shelter against sea urchin predation (Farina et al. 2008) and may alleviate predation in MPAs, smoothing differences between MPAs and control seagrass meadows. Moreover, the relevance of top-down control has been related to the size and abundance of efficient size-selective predator species (Coris julis and Diplodus spp.), which are comparatively more abundant in rocky habitats (A. GarcíaRubies pers. comm.). Individuals may escape from predation when they attain test sizes larger than ca. $4 \mathrm{~cm}$ 
(Sala 1997). In some MPAs, however, the strength of top-down processes may involve a longer period of recovery, due to the extreme longevity of Paracentrotus lividus (ca. $10 \mathrm{yr}_{\text {; }}$ Crapp \& Willis 1975) compared to the time period required to detect changes in the increase in fish populations (at least 3 to $4 \mathrm{yr}^{\text {; García- }}$ Charton et al. 2004).

As already described for Indo-Pacific seagrass beds (Alcoverro \& Mariani 2004), fishing restrictions appear to affect both herbivores in an opposite manner, increasing fish herbivory while decreasing sea urchin herbivory pressure, although sea urchins are largely affected by other processes. As a result, the 2 sites with major herbivory pressure (fish and sea urchin together) have a completely different function, as one is a fishing-protected meadow dominated by Sarpa salpa (Banyuls MPA) and the other, an unprotected meadow dominated by Paracentrotus lividus (Giverola). In any case, the effect of protection did not disrupt the trends of increased herbivory observed with decreasing meadow size, since $S$. salpa was the only species affected (see Moericke et al. 1975, Fahrig \& Paloheimo 1987, for similar concentration effects in other species).

To conclude, the results presented here suggest that fishing pressure and the loss or deterioration of seagrass habitat can modify the demographic structure of herbivores in Posidonia oceanica ecosystems and alter the functioning of shallow seagrass meadows. Seagrass area loss and fragmentation due to increasing anthropogenic pressure would imply that the remnant seagrass would be further exposed to increased herbivory rates, eventually leading to additional decline. Therefore, the inclusion of critical seagrass areas within the design of future marine reserves should deserve more attention to prevent possible overgrazing events. In the present study we detected large differences in herbivory rates related to the meadow size gradient examined. This raises some key questions that require further research, such as examining the threshold of herbivory that can be tolerated by a seagrass meadow without deterioration. In any case, we have provided evidence that herbivory in marine systems is not only controlled by features of the populations or communities concerned, but also by landscape features, highlighting the importance of including this reciprocal perspective in conservation concerns.

Acknowledgements. This work was supported by a FI scholarship from the Departament d'Universitats, Recerca I Societat de la Informació (DURSI, Generalitat de Catalunya) to P. P., and the CGL2007-66771-C02/BOS project funded by the Spanish Ministry of Science and Technology. We thank D. Piorno and E. Gacia for permission to use our shared data from Port-Cros. The authors thank the Réserve Naturelle Marine de Cerbère-Banyuls and the Parc national de PortCros for site guidance and T. Thibaut for assistance during fieldwork. We are also grateful to M. Pérez for comments.

\section{LITERATURE CITED}

Abesamis RA, Russ GR (2005) Density-dependent spillover from a marine reserve: long-term evidence. Ecol Appl 15: 1798-1812

Alcoverro T, Mariani S (2004) Patterns of fish and sea urchin grazing on tropical Indo-Pacific seagrass beds. Ecography 27:361-365

Augier H, Boudouresque CF (1976) Végétation marine de l'île de Port-Cros (parc national). XIII documents pour la carte des peuplements benthiques. Trav Sci Parc Nation, PortCros 2:9-22

Bell JD (1983) Effects of depth and marine reserve fishing restrictions on the structure of a rocky reef fish assemblage in the north-western Mediterranean Sea. J Appl Ecol 20:357-369

Bender DJ, Contreras TA, Fahrig L (1998) Habitat loss and population decline: a meta-analysis of the patch size effect. Ecology 79:517-533

Bowman J, Cappuccino N, Fahrig L (2002) Patch size and population density: the effect of immigration behavior. Conserv Ecol 6:9-16

Bukovinszky T, Potting RPJ, Clough Y, van Lenteren JC, Vet LEM (2005) The role of pre- and post- alighting detection mechanisms in the responses to patch size by specialist herbivores. Oikos 109:435-446

Christensen MS (1978) Thropic relationships in juvenile fishes of three species of Sparid fishes in the South African marine littoral. Fish Bull 76:389-401

Crapp GB, Willis MB (1975) Age determination in the sea urchin Paracentrotus lividus (Lamarck), with notes on the reproductive cycle. J Exp Mar Biol Ecol 20:157-178

Cyr H, Pace ML (1993) Magnitude and patterns of herbivory in aquatic and terrestrial ecosystems. Nature 361:148-150

Dance C (1987) Patterns of activity of the sea urchin Paracentrotus lividus in the Bay of Port-Cros (Var France Mediterranean). PSZN I: Mar Ecol 8:132-142

Fahrig L, Paloheimo JE (1987) Interpatch dispersal of the cabbage butterfly. Can J Zool 65:616-622

Farina S, Tomas F, Prado P, Alcoverro T, Romero J (2008) Seagrass meadow structure alters interactions between the sea urchin Paracentrotus lividus and its predators. Mar Ecol Prog Ser (in press)

Francour P (1997) Fish assemblages of Posidonia oceanica beds at Port-Cros (France NW Mediterranean): assessment of composition and long-term fluctuations by visual census. PSZN I: Mar Ecol 18:157-173

Francour P (1999) A critical review of adult and juvenile fish sampling techniques in Posidonia oceanica seagrass beds. Nat Sicil 23:33-57

García-Charton JA, Pérez-Ruzafa A, Sánchez-Jerez P, BayleSempere JT, Reñones O, Moreno D (2004) Multi-scale spatial heterogeneity, habitat structure, and the effect of marine reserves on Western Mediterranean rocky reef fish assemblages. Mar Biol 144:161-182

García-Rubies A (1997) Estudi ecologic de les poblacions de peixos litorals sobre substrat rocós a la Mediterrània Occidental: efectes de la fondària el substrat l'estacionalitat i la protecció. PhD thesis, University of Barcelona

> Halpern B, Warner RR (2002) Marine reserves have rapid and long lasting effects. Ecol Lett 5:361-366

> Hambäck PA, Englund G (2005) Patch area population density and the scaling of migration rates: the resource concentration hypothesis revisited. Ecol Lett 8:1057-1065

> Harmelin-Vivien ML, Harmelin JG, Leboulleux V (1995) Microhabitat requirements for settlement of juvenile Sparid fishes on Mediterranean rocky shores. Hydrobiol 300-301:309-320 
Havelange S, Lepoint G, Dauby P, Bouquegneau JM (1997) Feeding of the Sparid fish Sarpa salpa in a seagrass ecosystem: diet and carbon flux. PSZN I: Mar Ecol 18: 289-297

Hereu B, Linares C, Diaz D, Dantart L and others (2003) Indicateurs de biodiversité en milieu marin: les échinodermes Fluctuations temporelles des peuplements d'échinodermes à Port-Cros 1982-2003. University of Barcelona, Barcelona

> Hilborn R, Stokes K, Maguire JJ, Smith T and others (2004) When can marine reserves improve fisheries management? Ocean Coast Manag 47:197-205

Jackson JBC, Kirby MX, Berger WH, Bjorndal KA, Bostford LW, Bourque BJ (2001) Historical overfishing and recent collapse of coastal ecosystems. Science 293:629-638

Jadot C, Ovidio M, Voss J (2002) Diel activity of Sarpa salpa (Sparidae) by ultrasonic telemetry in a Posidonia oceanica meadow of Corsiga (Mediterranean Sea). Aquat Liv Res 15:343-350

Jadot C, Donnaya A, Acolasb ML, Cornetc Y, Bégout Anrasb ML (2006) Activity patterns, home-range size, and habitat utilization of Sarpa salpa (Teleostei: Sparidae) in the Mediterranean Sea. ICES J Mar Sci 63:128-139

Kirsch KD, Valentine JF, Heck KL Jr (2002) Parrotfish grazing on turtlegrass Thalassia testudinum: evidence for the importance of seagrass consumption in food web dynamics of the Florida Keys National Marine Sanctuary. Mar Ecol Prog Ser 227:71-85

Kondoh M (2003) Habitat fragmentation resulting in overgrazing by herbivores. J Theor Biol 225:453-460

Kramer DL, Chapman MR (1999) Implications of fish home range size and relocation for marine reserve function. Environ Biol Fishes 55:65-79

- Macpherson E, Biagi F, Francour P, Garcia-Rubies A and others (1997) Mortality of juvenile fishes of the genus Diplodus in protected and unprotected areas in the western Mediterranean Sea. Mar Ecol Prog Ser 160:135-147

> McClanahan TR (2000) Recovery of a coral reef keystone predator Balistapus undulatus in East African marine parks. Biol Conserv 94:191-198

McClanahan TR, Arthur R (2001) The effect of marine reserves and habitat on populations of East African coral reef fishes. Ecol Appl 11:559-569

McClanahan TR, Muthiga NA, Kamukuru AT, Machano H, Kiambo RW (1999) The effects of marine parks and fishing on coral reefs of northern Tanzania. Biol Conserv 89: 161-182

Moericke V, Prokopy RJ, Berlocher S, Bush GL (1975) Visual stimuli eliciting attraction of Rhagoletis pomonella flies to trees. Entomol Exp Appl 18:497-507

> Ogden JC, Lobel PS (1978) The role of herbivorous fishes and urchins in coral reef communities. Environ Biol Fishes 3: 49-63

Otway ST, Hector A, Lawton JH (2005) Resource dilution effects on specialist herbivores in a grassland biodiversity experiment. J Anim Ecol 74:234-240

Pauly D, Christensen V, Guénette S, Pitcher TJ and others (2002) Towards sustainability in world fisheries. Nature 418:689-695

> Peterson BJ, Rose CD, Rutten LM, Fourqurean JW (2002) Disturbance and recovery following catastrophic grazing: studies of a successional chronosequence in a seagrass bed. Oikos 97:361-370

> Pinnegar JK, Polunin NVC, Francour P, Badalamenti F and others (2000) Trophic cascades in benthic marine ecosystems: lessons for fisheries and protected-area management. Environ Conserv 27:179-200
Prado P, Mariani S, Alcoverro T, Romero J (2006) Ecological patterns associated to the demographic structure of Paracentrous lividus populations in Posidonia oceanica beds. In: Mediterranean Seagrass Workshop 2006, Abstracts Marsascala, Malta, p 94

Prado P, Tomas F, Alcoverro T, Romero J (2007) Extensive direct measurements of Posidonia oceanica defoliation confirm the importance of herbivory in temperate seagrass meadows. Mar Ecol Prog Ser 340:63-71

Roberts CM, Bohnsack JA, Gell F, Hawkins JP, Goodridge R (2001) Effects of marine reserves on adjacent fisheries. Science 294:1920-1923

Rochet MJ, Trenkel VM (2003) Which community indicators can measure the impact of fishing? A review of proposals. Can J Fish Aquat Sci 60:86-99

Root RB (1973) Organization of a plant-arthropod association in simple and diverse habitats: the fauna of collards (Brassica oleracea). Ecol Monogr 43:95-124

Ros J, Olivella I, Gili JM (1984) Els sistemes naturals de les Illes Medes Arxius de la Secció de Ciències LXXIII. Institut d'Estudis Catalans, Barcelona

Sala E (1997) Fish predators and scavengers of the sea urchin Paracentrotus lividus in protected areas of the north-west Mediterranean. Mar Biol 129:531-539

Sala E, Boudouresque CF, Harmelin-Vivien M (1998) Fishing, trophic cascades, and the structure of algal assemblages: evaluation of an old but untested paradigm. Oikos 82: $425-439$

Sánchez-Jerez P, Ramos Esplá AA (1996) Detection of environmental impacts by bottom trawling on Posidonia oceanica (L) Delile meadows: sensitivity of fish and macroinvertebrate communities. J Aquat Ecosyst Health 5:239-253

Shears NT, Babcock RC (2003) Continuing trophic cascade effects after 25 years of no-take marine reserve protection. Mar Ecol Prog Ser 246:1-16

Short F, Wyllie-Echeverria S (1996) Natural and humaninduced disturbance of seagrasses. Environ Conserv 23: $17-27$

Szmant AM (2002) Nutrient enrichment on coral reefs: is it a major cause of coral reef decline? Estuaries 24:743-766

Tahvanainen JO, Root RB (1972) The influence of vegetational diversity on the population ecology of a specialised herbivore Phyllotera cruciferae (Coleoptera: Crhysomelidae). Oecologia 10:321-346

> Tomas F, Turon X, Romero J (2005) Seasonal and small-scale spatial variability of herbivory pressure on the temperate seagrass Posidonia oceanica. Mar Ecol Prog Ser 301: 95-107

Underwood AJ (1981) Techniques of analysis of variance in experimental marine biology and ecology. Oceanogr Mar Biol Annu Rev 19:513-605

> Underwood AJ (1993) The mechanisms of spatially replicated sampling programmes to detect environmental impacts in a variable world. Aust J Ecol 18:99-116

Valentine JF, Heck KL Jr (1999) Seagrass herbivory: evidence for the continued grazing of marine grasses. Mar Ecol Prog Ser 176:291-302

Vander Walt BA, Govender A (1996) Stock assessment of Sarpa salpa (Pisces:Sparidae) off the KwaZulu/Natal coast South Africa. S Afr J Mar Sci 17:195-204

Vergés A (2007) Strategies of defence of marine macrophytes. PhD thesis, University of Barcelona

Verlaque M (1990) Relations entre Sarpa salpa (Linnaeus 1758) (Teleosteen Sparidae) les autres poissons brouteurs et le phytobenthos algal Mediterraneen. Oceanol Acta 13:373-388

Submitted: February 4, 2008; Accepted: July 23, 2008

Proofs received from author(s): October 23, 2008 